dysthymia, for depressed patients in primary care, bipolar patients, drug abusers, and for bulimia. These adaptations, and the clinical trial data, as well as the trials under way, have all been described in our recent book New Applications of Interpersonal Psychotherapy (Washington, DC: APP, 1993).

While I agree with Dr Holmes' premise about the importance of Bowlby's theory of attachment as a foundation for psychotherapy, I disagree that $\mathrm{Dr}$ Bowlby's work has been ignored in psychotherapy.

Division of Clinical Genetic Epidemiology

MYRna M. WeisSman College of Physicians \& Surgeons of Columbia

University

New York 10032

USA

\section{Tricyclic-induced seizures and absent ECT response}

SIR: The main point of the report by Drs Byrne \& Silverstone (BJP, November 1993, 163, 691-692) was that the patient responded well to a seizure induced by amitriptyline but not to electroconvulsive therapy (ECT).

My personal experience is that seizures induced chemically tend to last longer than those produced by ECT. In this particular case, the amitriptylineinduced seizure lasted 60 seconds, and this is probably two to three times longer than that produced by an average ECT application. Since seizure duration has been reported to be related to clinical outcome (Abrams, 1992) it is possible that the improvement following the amitriptyline-induced seizure was due to its duration. Since this patient had a propensity to develop seizures on amitriptyline, it might have been more appropriate to put the patient on an antidepressant with a low seizure activity profile. Doxepin (Ojemann et al, 1983) may be one of the safest antidepressants for treating the depressed patient at risk of seizures. Amitriptyline and fluoxetine (which was also tried) are both associated with a greater propensity to cause seizures in susceptible patients. Krijzer et al (1984) examined nine antidepressants and found amitriptyline to be the most proconvulsive. In addition, fluoxetine, when compared with other selective serotonin reuptake inhibitors, has been reported to be associated with more seizures (Ware \& Stewart, 1989). Doxepin would have both reduced the risk of seizure and avoided the need to add carbamazepine and thus introduce the risk of neutropenia.

AвRAMS, R. (1992) Electroconiulsive Therapy (2nd edn). Oxford: Oxford University Press.
Krijzer, F., Snelder, M. \& Bradford, D. (1984) Comparison of the (pro)convulsive properties of fluvoxamine and clovoxamine with eight other antidepressants in an animal model. Neuropsychobiology, 12, 249-254.

OjemanN, L. M., Friel, P. N., Trejo, W. L., et al (1983) Effect of doxepin on seizure frequency in depressed epileptic patients. Neurology, 33, 646-648.

WARE, M. R. \& StEWART, R. B. (1989) Seizures associated with fluoxetine therapy. DICP Annals of Pharmacotherapy, 23, 428.

High Royds Hospital

S. Curran

Ilkley LS29 6AQ

\section{Cannabis toxic psychosis while on disulfiram}

SIR: A 36-year-old man who had been on disulfiram (Antabuse) for a month smoked cannabis as a substitute for alcohol. He immediately developed an acute confusional state (with lowered level of consciousness, disorientation, misperceptions, believing the orange juice he was drinking was wine, and rambling, repetitive speech). After three days this changed to a manic picture, which was unusual in that the overactivity occurred in sudden bursts with relative normality between. This died down after 48 hours, during which he was receiving chlorpromazine. At the request of him and his wife he continued on disulfiram (without cannabis), with no further such problems. He had once taken cannabis, many years before, with no ill effects. The manufacturers of Antabuse had had one previous such report (Lacoursiere \& Swatek, 1983).

LACOUrsiere, R. B. \& Swatek, R. (1983) Adverse interaction between disulfiram and marijuana: a case report. American Journal of Psychiatry, 140, 242-244.

JAMEs MACKIE

Bangour Village Hospital Donald Clark

Broxburn

West Lothian EH52 61W

\section{Pain and seasonal affective disorder}

SIR: I found the conclusion of Dilsaver et al (BJP, November 1993, 163, 672-674) difficult to understand. Why should clinicians single out patients with wintertime depression to question about the experience of pain? Surely it is depression per se, no matter what its periodicity, which has been associated with pain. The authors, quoting von Knorring (1975) and others, state that $50-60 \%$ of all depressed patients experience pain. Of their winter depressives, $51.2 \%$ complained of pain. To my mind, this lack of a 
difference favours Oswald's (1986) healthy scepticism about the uniqueness of seasonal affective disorder.

Oswald, I. (1986) What is seasonal affective disorder? British Medical Journal, 292, 1326.

VON KNORRING, L. (1975) The experience of pain in depressed patients. Neuropsychobiology, 1, 155-165.

Newcastle Hospital

Brian O'SHEA

Greystones

County Wicklow

Ireland

\section{The rarity of mania in Down's syndrome}

SIR: Drs Cooper \& Collacott (BJP, June 1993, 162, 739-743) reviewed seven case reports of mania in people with Down's syndrome. The authors suggest that the rarity of mania in these patients, especially women, might be due to unique biochemical characteristics of this syndrome, perhaps with gender differences.

One problem with this interpretation is the lack of validated diagnostic criteria and assessment instruments for people with mental retardation (Campbell \& Malone, 1991; Sturmey, 1993). Impaired language and intellect can make it difficult to assess symptoms in these patients, and there is a tendency to rely on subjective interpretations of behavioural observations to make psychiatric diagnoses. Indeed, behaviour problems are a common reason for psychiatric referral of these patients (Aman, 1987; Howland, 1992). Behaviour problems often are simply attributed to the mental retardation, or are loosely diagnosed as an organic brain syndrome, rather than recognised as a possible manifestation of an underlying comorbid psychiatric disorder. Behaviour problems can also mask other symptoms. This, together with the difficulty of assessing cognitive symptoms due to impaired language and intellect, can lead to a failure to diagnose specific psychiatric disorders (Howland, 1992). In addition, the known association of Down's syndrome with the early onset of Alzheimer's disease might also bias doctors to attribute any psychiatric or behavioural symptoms to the early stages of dementia.
A second problem is the confounding effect of treatment on the recognition of psychiatric symptoms in people with mental retardation. Neuroleptics, anticonvulsants, and sedatives are the most commonly used drugs in these patients, typically to control behaviour problems (Aman, 1987). These drugs have antimanic effects, and their widespread but non-specific use to treat behaviour problems might thus lead to a spuriously low prevalence of mania. The confounding effect of anticonvulsant treatment has been similarly suggested to explain the rarity of mania in some patients with epilepsy (Howland, 1993).

These diagnostic and treatment issues provide an alternative and, I believe, more likely explanation for the rarity of mania in Down's syndrome. Future research investigating the clinical and biological aspects of mania and other psychiatric disorders in people with Down's syndrome should carefully control for these important confounding factors.

Aman, M. G. (1987) Overview of pharmacotherapy: current status and future directions. Journal of Mental Deficiency Research, 31, $121-130$.

Campbell. M. \& Malone, R. P. (1991) Mental retardation and psychiatric disorders. Hospital and Community Psychiatry, 42, 374-379.

Howland, R. H. (1992) Fluoxetine treatment of depression in mentally retarded adults. Journal of Nervous and Mental Disease. 180, 202-205.

(1993) Bipolar disorder associated with primary generalised epilepsy. British Journal of Psychiatry, 162, 699-700.

StURMEY, P. (1993) The use of DSM and ICD diagnostic criteria in people with mental retardation. Journal of Nervous and Mental Disease, 181, 38-41.

ROBERT H. HOWLAND

Western Psychiatric Institute and Clinic

University of Pittsburgh School of Medicine.

Pittsburgh

Pennsylvania 15213

$U S A$

\section{CORRIGENDUM}

$B J P$, January 1994, 164, 128. "Benzodiazepine fatal poisonings": the third sentence should read "We were surprised by the high number of benzodiazepines not only involved in attempted suicide $(46.3 \%$ of all drugs taken, single or in combination with other drugs) but also in completed suicide $(43.8 \%)$ ". 